clear of breakers is as true to-day as the day it was spoken. No doubt Dr. Woodbridge has added some enthusiasm to our modern principles of typhoid fever treatment. But let us not lose our power of reasoning and accurate observation until we see more of this treatment. I read with interest his paper at the Baltimore meeting, and with more interest the discussion by Drs. Pepper and Osler, in which the former stated that each time we had discovered a panacea in medicine or plan of treatment for this disease, we were disappointed in the next epidemic by a frightful mortality.

Typhoid fever, in all probability, has existed for ages past, but it was left for an American physician about sixty years ago to catalogue it as a distinct disease. Now from one decade to another we are learning to treat it better, each enthusiast on the subject adding his mite. Dr. Graves, of Dublin, wanted it engraved on his tombstone how he fed fevers. And now let me ask Dr. Woodbridge and his followers if we take from a typhoid fever patient proper hygienic surroundings, proper feeding and good nursing, what good will his or any other treatment do? My partner, Dr. C. J. Lidikay, and I bought of Parke Davis \& Co. the Woodbridge medicines and commenced the use of them last year in good faith. Our first patient was a most favorable one for the treatment, a formerly healthy girl 12 years old, in a family with two other cases of typhoid fever. We followed the plan in minute detail, and the fever went through its regular stages, lasted four weeks; and we could not. see that the treatment did any more good than any other sensible plan of management. We tried it faithfully on fourteen eases in two families on the same farm who used the water out of a polluted well. It never modified nor shortened the duration of a single case. for they all went through the regular stages. They all got well but one, who took double parotitis while convalescing, Five other children out of one other family who visited this farm took the fever and two died, one from hemorrhage and one from the severity of the lesions after four weeks' sickness. We treated over forty cases of all grades of intensity with only the loss of these three cases. And at last treated my only child last October through a typhoid fever. I tried the Woodbridge treatment up to the second week, when her stomach rebelled against the soft capsules and emulsion of the same. We then nursed her with just enough medicine to control symptoms. The fever reached 100 deegrees four successive days the latter part of the third week, and we have nursed her three months since to tide her over the effect of this awful fever, encountering several dangerous breakers along the line.

Dr. Osler said the best thing he could see about this treatment was that the medicine was harmless. Woodbridge has emphasized one principle that will last, and that is that the bowel will stand more cleaning out with less danger than was formerly thought. Typhoid fever still holds sway over patients. We are between scylla and Charybdis in its treatment, and it is a plague to any family or community.

W. F. Batman.

The Royal Colleges and the Women.

To the Editor: The recent action of the Royal Colleges of Physicians and Surgeons, England, in declining, by a narrow vote, to grant women their diplomas, is indicative both of the remaining prejudice against women doctors and the progress of their efforts for complete recognition by the profession.

The two chief arguments against them, aside from natural unfitness, were that they commonly entered the profession from improper motives, and that they had contributed nothing toward its advance. It is thus quite evident that some of our professional brethren across the water, have been expecting too much from the "gentler sex," for the very same arguments will apply equally well to not a few of the masculine denomination. Also the fact seems to have been overlooked that the "new" woman is still comparatively new and has hardly had time to evolve that increase of brain and the desexing process which are finally to fit her with that keen, cool, deliberative mind requisite to rule the earth on scientific principles. The "new" woman may not possess the charms of a Cleopatra, but she craves her power and if she can not attain it the one way, why should she not try another? There can be but little objection to giving her every privilege within the bounds of propriety, for in so doing her superiority in some department of medicine will the sooner be demonstrated, or her mania the sooner ended.

Doubtless some enter the profession from the loftiest motives, and do credit to it, and whether or not, after all is considered, they have mistaken their calling, is for them individually to judge. It is to be hoped that ere long they will have no occasion to complain of unequal privileges in such an enlightened city as London.

J. S. C.

\section{A Knotted Umbilical Cord.}

Berwyn, Ill., Jan. 16, 1896.

To the Editor: A rather unique case occurred in my obstetric practice at this place last week. Mrs. S., who was under my care and expected to be confined late in February, sent for me early the morning of January 10. Upon arriving at the house $I$ found my patient in the midst of labor, regular pains, very frequent and severe. Examination revealed dilated os, breech presentation, no evidence of fetus being alive. A short time later delivery was accomplished. The fetus was dead. Stage of development was that of a seven-months' fetus. It weighed about three pounds, and gave evidence of having been dead some little time, as it was considerably macerated. Upon examination of the cord I found a tight knot about midway between fetus and placenta. This undoubtedly had caused fetal death, which precipitated labor. The mother had not felt life for several days previously. Possibly this case may be of interest as evidence that the fetus does enjoy considerable latitude of motion in utero.

Very respectfully yours, ARthur MacNeal, M.D.

\section{Suspensio Uteri or: Ventro-Fixation of the Cterus -its Influence upon Pregnancy and Labor.}

To the Editor:-Having recently had some unfortunate experience concerning suspensio uteri upon parturition, I feel that it is highly important that this question be settled in an authoritative way as soon as possible. The only way to determine the question is by studying the actual results as seen in the practice of all operators. I will be much indebted to any one having had a case of pregnancy following suspension of the uterus, if he will communicate the details of the case or cases to me. Very truly yours, Charles P. Noble. 1637 N. Broad St., Philadelphia.

\section{Sexual Perversion.}

Washington, D. C., Jan. 20, 1896.

To the Editor:-Having noticed in two of your late issues that correspondents ask for the definition of the word tribadism, I will call attention to the very full and comprehensive article by Dr. Irving C. Rosse, of Washington, D. C., on "Unnatural Crimes," in vol. Ir, p. 493 , of Witthaus and Becker's "Medical Jurisprudence." In this valuable and instructive paper, your correspondents will find detailed information as to the various forms of sexual perversion as observed by neurologists and as treated from the view point of medico-legal knowledge. Trusting the reference, as already given above, may be of service to your corespondents. I remain, yours respectfully,

2315 Pennsylvania A venue, N. W. 